\title{
The impact of the metabolic syndrome and its components on the incidence of ischemic heart disease and stroke: the Japan public health center-based study
}

\author{
Hiroyuki Noda ${ }^{1,2}$, Hiroyasu Iso ${ }^{1}$, Isao Saito ${ }^{3}$, Masamitsu Konishi ${ }^{3}$, Manami Inoue $^{4}$ and Shoichiro Tsugane ${ }^{4}$, \\ for the JPHC Study Group
}

In this study, we aimed to examine the impact of the metabolic syndrome and its components on the risk of cardiovascular disease among a relatively less-obese population. A total of 8249 men and 15064 women, aged 40-69 years, with no history of ischemic heart disease, stroke and/or cancer completed a risk-factor survey between 1993 and 1995. The metabolic syndrome was defined based on modified criteria of the American Heart Association/National Heart, Lung, and Blood Institute (AHA/NHLBI) and the International Diabetes Federation (IDF). Systematic cardiovascular surveillance was carried out throughout 2003, and 693 events of ischemic heart disease and stroke were identified. We observed significant associations of the metabolic syndrome with the risk of ischemic heart disease and ischemic stroke, but not with hemorrhagic stroke. The multivariable hazard ratio $(95 \%$ confidence interval) of ischemic heart disease among men for the metabolic syndrome based on the AHA/NHLBI criteria was 2.25 (1.44-3.51) and that of ischemic stroke was $1.88(1.40-2.52)$. The respective hazard ratios for the metabolic syndrome based on the IDF criteria were $1.61(0.99-2.64)$ for ischemic heart disease and $1.94(1.41-2.68)$ for ischemic stroke. The population-attributable fraction (PAF) of the metabolic syndrome based on the AHA/NHLBI criteria was higher than that based on the IDF criteria: 19 vs. $12 \%$ ( $P$ for difference $=0.003)$ for ischemic cardiovascular disease among men, because non-overweight men with $\geqslant 2$ risk factors were also at high risk ( $20 \%$ of the PAF). Our data suggest that the metabolic syndrome based on the AHA/NHLBI criteria predicts ischemic cardiovascular disease better than the syndrome based on the IDF criteria, because of the exclusion of non-overweight high-risk individuals from the reference group.

Hypertension Research (2009) 32, 289-298; doi:10.1038/hr.2009.14; published online 27 February 2009

Keywords: cardiovascular disease; follow-up studies; risk factors; stroke

\section{INTRODUCTION}

The metabolic syndrome has been addressed as one of the major public health targets worldwide. ${ }^{1-2}$ Some committees have engineered definitions of the metabolic syndrome; $;^{3-7}$ the Japanese government started a nation-wide intervention strategy for the metabolic syndrome in April 2008. ${ }^{8}$

Traditionally, the metabolic syndrome involves obesity, ${ }^{9}$ leads to a cluster of other cardiovascular risk factors and increases the risk of cardiovascular disease. ${ }^{10-17}$ The American Heart Association/National Heart, Lung, and Blood Institute (AHA/NHLBI) defined the metabolic syndrome as a constellation of cardiovascular risk factors including obesity, ${ }^{5}$ whereas the criteria of the International Diabetes
Federation (IDF) ${ }^{6}$ were based on the presence of obesity. The metabolic syndrome, by the IDF criteria, is defined as a condition of obese persons with certain cardiovascular risk factors; thus, non-obese persons are not diagnosed with the metabolic syndrome, even if they have any of these cardiovascular risk factors. Earlier Japanese studies showed that underweight individuals also had a high risk of hemorrhagic stroke, ${ }^{18}$ due to various pathological mechanisms. ${ }^{19}$ It is of value to examine the criteria of the metabolic syndrome that effectively predict the risk of cardiovascular disease among lessobese populations, such as the Japanese. ${ }^{20}$

We examined the contribution of the metabolic syndrome and its components to the incidence of ischemic heart disease and stroke

${ }^{1}$ Public Health, Department of Social and Environmental Medicine, Graduate School of Medicine, Osaka University, $2-2$ Yamadaoka, Suita, Osaka, Japan; ${ }^{2}$ Harvard Center for Population and Development Studies, Harvard School of Public Health, Cambridge, Massachusetts, USA; ${ }^{3}$ Department of Public Health, Social Medicine and Medical Informatics, Ehime University Graduate School of Medicine, Shitsukawa, Toon, Ehime, Japan and ${ }^{4}$ Epidemiology and Prevention Division, Research Center for Cancer Prevention and Screening, National Cancer Center, 5-1-1 Tsukiji, Chuo-ku, Tokyo, Japan

Correspondence: Professor H Iso, Public Health, Department of Social and Environmental Medicine, Osaka University, Graduate school of Medicine, 2-2 Yamadaoka, Shuita, Osaka 565-0871 Japan.

E-mail: iso@pbhel.med.osaka-u.ac.jp

Received 17 July 2008; revised 12 January 2009; accepted 16 January 2009; published online 27 February 2009 
among Japanese men and women, among whom there is a low prevalence of obesity.

\section{METHODS}

\section{Study cohort}

We used two cohorts in this study. The Japan Public Health Center-based Prospective Study (JPHC Study) initiated the first (Cohort I) and the second cohort (Cohort II), registered in 27 administrative districts supervised by nine public health centers. ${ }^{21}$ The subjects were identified using population registries maintained by the local municipalities. Data regarding lifestyle, serum total and high-density lipoprotein (HDL) cholesterol, serum triglycerides, glucose, blood pressure, height in stocking feet and weight in light clothing were available for 8582 men and 15521 women aged 40-69 years; these subjects responded to the self-administered questionnaire and undertook health examinations conducted by municipal governments in 1995 (Cohort I) and 1993-1994 (Cohort II). Together, these questionnaires and health examinations represented the baseline survey. We excluded the subjects who reported having cancer, myocardial infarction, angina pectoris or stroke at the baseline survey, leaving 23313 people ( 8249 men and 15064 women) for analysis. We informed all study subjects of the study details. The protocol of the study was approved by the institutional review board of the National Cancer Center, Tokyo, Japan.

The subjects were followed-up from the date of the baseline survey to 31 December 2003. Residence and survival were confirmed annually using the residential registers maintained by each municipality. For subjects who moved out of the study area, we used the data reported by the municipal office within the area to which they had moved. In Japan, residency and death registration are required by law, and the registries are believed to be complete. Information on the cause of death was obtained through the death certificate provided by the Ministry of Health, Labor, and Welfare after the Ministry of Internal Affairs and Communications granted permission. The study protocol was approved by the Human Ethics Review Committees of the National Cancer Center and the University of Tsukuba.

\section{Baseline survey}

Serum total and HDL cholesterol and triglycerides were measured in 23 laboratories. The precision and accuracy of lipid measurement in all laboratories were satisfactory, according to the Osaka Medical Center for Health Science and Promotion, a member of the Cholesterol Reference Method Laboratory Network. ${ }^{22}$ Arterial blood pressure was measured using a standard mercury sphygmomanometer applied to the right arm of the seated participant after a 5-min rest. Height in stocking feet and weight in light clothing were measured. Body mass index (BMI) was calculated as weight $(\mathrm{kg})$ divided by the square of the height in meters $\left(\mathrm{m}^{2}\right)$. A self-administrated questionnaire was carried out to ascertain the smoking status, the number of cigarettes smoked per day and the usual weekly intake of alcohol in go units (a Japanese traditional unit of volume corresponding to $23 \mathrm{~g}$ ethanol).

A modified definition by the AHA/NHLBI ${ }^{5}$ and the $\mathrm{IDF}^{6}$ was used to categorize the subjects according to the number of components of the metabolic syndrome shown. As waist circumference was not measured in this study, BMI $\geqslant 25.0 \mathrm{~kg} \mathrm{~m}^{-2}$ was used as the criterion for obesity; this BMI level was reported to correspond well with the Asian criterion for high waist circumference of $\geqslant 85 \mathrm{~cm}$ in men and $\geqslant 90 \mathrm{~cm}$ in women and $100 \mathrm{~cm}^{2}$ of visceral fat area. ${ }^{23}$ The components of the metabolic syndrome were defined as follows: (1) high blood pressure: blood pressure $\geqslant 130 / 85 \mathrm{~mm} \mathrm{Hg}$ and/or medication use; (2) high glucose: glucose $\geqslant 5.55 \mathrm{mmoll}^{-1}$ (100 mg per $100 \mathrm{ml})$ fasting or $\geqslant 7.77 \mathrm{mmoll}^{-1}(140 \mathrm{mg}$ per $100 \mathrm{ml})$ non-fasting and/or on treatment; (3) low HDL cholesterol: HDL cholesterol $<1.03 \mathrm{mmoll}^{-1}$ ( $40 \mathrm{mg}$ per $100 \mathrm{ml}$ ) for men and $<1.29 \mathrm{mmoll}^{-1}(50 \mathrm{mg}$ per $100 \mathrm{ml})$ for women; (4) high triglycerides: high serum triglycerides $\geqslant 1.69 \mathrm{mmoll}^{-1}$ $(150 \mathrm{mg}$ per $100 \mathrm{ml})$; and $(5)$ overweight: $\mathrm{BMI} \geqslant 25.0 \mathrm{~kg} \mathrm{~m}^{-2}$. The metabolic syndrome was defined as the presence of three or more of the components (high blood pressure, high glucose, low HDL cholesterol, high triglycerides and overweight) according to the modified criteria of the AHA/NHLBI and the presence of two or more of the cardiovascular risk factors (high blood pressure, high glucose, low HDL cholesterol and high triglycerides) among individuals who were overweight according to the modified criteria of the IDF.

\section{Confirmation of ischemic heart disease and stroke subtypes}

For confirmation of cardiovascular events, a total of 78 hospitals were registered in the sampling area of the study cohort. ${ }^{24}$ All were major hospitals capable of treating patients with acute ischemic heart disease and stroke. To reduce uncaptured events, we also sent follow-up questionnaires to participants and reviewed death certificates for identifying suspected cardiovascular events. Therefore, all suspected events of cardiovascular disease were collected using ascertainment resources, including active patient notification, follow-up questionnaires and death certificate diagnoses. For the final diagnosis of cardiovascular events, physicians blinded to the patients' lifestyle data reviewed the medical records at each hospital.

The details of the surveillance for ischemic heart disease were described earlier. ${ }^{25}$ Myocardial infarction was confirmed in the medical records according to the criteria of the Multinational MONItoring of trends and determinants in CArdiovascular disease (MONICA) project, ${ }^{26}$ which requires evidence from electrocardiograms, cardiac enzymes and/or autopsy. When such workup was not performed and typical chest pain was present, a probable diagnosis was made. In the absence of diagnosis for myocardial infarction, deaths that occurred within $1 \mathrm{~h}$ from the onset of symptoms were regarded as sudden cardiac deaths.

Strokes were confirmed according to the criteria of the National Survey of Stroke, ${ }^{27,28}$ which requires a constellation of neurological deficits of sudden or rapid onset lasting at least $24 \mathrm{~h}$ or until death. For each subtype of stroke (namely, hemorrhagic stroke (intraparenchymal hemorrhage and subarachnoid hemorrhage) or ischemic stroke (thrombotic or embolic stroke)), a definite diagnosis was established based on the examination of computer tomographic scan, magnetic resonance images or autopsy.

\section{Statistical analysis}

Outcome was defined as the new development of a primary ischemic heart disease or stroke during the study period. For each subject, person-months of follow-up were calculated from the baseline questionnaire collected to the first endpoint, death, emigration or 1 January 2004, whichever came first. Overall, $3 \%$ of the subjects had moved out of the communities (740 people) or were lost to follow-up (45 people) and were treated as censored.

Sex-specific hazard ratios of ischemic heart disease, stroke subtypes and the respective $95 \%$ confidence intervals (95\% CI) were calculated with reference to the risk of individuals without the metabolic syndrome, without each individual component or with none of these components, using the Cox proportional hazards model. The multivariable hazard ratios were adjusted for potential confounding factors, including age at baseline (years), study area (nine public health center areas), time since last meal $(<8 \mathrm{~h} v$ s. $\geqslant 8 \mathrm{~h})$, total cholesterol levels (mg per $100 \mathrm{ml}$ ), smoking status (never smoked, ex-smokers, $<20$ cigarettes per day, $20-29$ cigarettes per day, $\geqslant 30$ cigarettes per day) and ethanol intake (non-drinkers, occasional drinkers ( $<75$ or $75-149 \mathrm{~g}$ per week), $150-299,300-449$, or $\geqslant 450 \mathrm{~g}$ per week). The sex-specific association between the metabolic syndrome and the risk of cardiovascular disease was examined, stratified by the presence or absence of overweight. We also calculated the population-attributable fraction (PAF) to examine the contribution of the metabolic syndrome and its components to the risk of cardiovascular disease, using multivariable hazard ratios and the proportion of cases in each category. ${ }^{29}$ The PAF was estimated as $\mathrm{pd} \times(\mathrm{HR}-1) / \mathrm{HR}$, where $\mathrm{pd}$ is the proportion of cases falling into the category and HR the hazard ratio in the category. The 95\% confidence limits (95\% CL) for the PAF were calculated using the bootstrap method. ${ }^{30}$

All statistical tests were two-sided and a $P$-value $<0.05$ was regarded as statistically significant. All statistical analyses were conducted using the SAS, version 9.13 (SAS Institute, Inc., Cary, NC, USA).

\section{RESULTS}

A total of 23313 people ( 8249 men and 15064 women) were followed for a median of 11.0 years; 395 men and 298 women presented with cardiovascular disease as either ischemic heart disease (82 men and 40 women) or stroke (314 men and 258 women). Ischemic heart disease included 95 definite myocardial infarctions, 9 probable myocardial infarctions and 18 sudden cardiac deaths. We also identified the stroke 
subtypes: ischemic stroke (206 men and 142 women) or hemorrhagic stroke (108 men and 116 women). Hemorrhagic stroke was classified into either intraparenchymal hemorrhage ( 90 men and 70 women) or subarachnoid hemorrhage ( 18 men and 46 women). Of the total cardiovascular disease events, the percentage of ischemic cardiovascular disease (ischemic heart disease and ischemic stroke combined) was $72.9 \%$ in men and $61.1 \%$ in women. The incidence of stroke (398 incidents per 100000 person-years in men and 172 incidents per 100000 person-years in women) was 3.8-fold higher in men and 6.5fold higher in women than that of ischemic heart disease (104 incidents per 100000 person-years in men and 27 incidents per 100000 person-years in women). With regard to stroke incidence, the percentage of intraparenchymal hemorrhage was $29 \%$ in men and $27 \%$ in women.

Men were older and had higher mean systolic and diastolic blood pressure, serum glucose and triglycerides compared with women. Moreover, men had lower mean total and HDL cholesterol and BMI compared with women (Table 1). Men were more likely to use medication for diabetes, drink heavily, smoke and have metabolic syndrome; however, they were less likely to use medication for hypertension. The percentage of obesity $\left(\mathrm{BMI} \geqslant 30 \mathrm{~kg} \mathrm{~m}^{-2}\right)$ was $2.3 \%$ in men and $4.0 \%$ in women.

We showed a significant increased risk of ischemic cardiovascular disease with regard to each component of the metabolic syndrome in men (Table 2). The multivariable hazard ratio of ischemic cardiovascular disease among men was 2.37 (1.72-3.25) for high blood pressure,

Table 1 Sex-specific baseline characteristics of cardiovascular risk factors, the metabolic syndrome based on modified criteria of the American Heart Association/National Heart, Lung, and Blood Institute (AHA/NHLBI) and the International Diabetes Federation (IDF) and its components

\begin{tabular}{|c|c|c|c|}
\hline & \multicolumn{2}{|c|}{ Means/percentages } & \multirow[b]{2}{*}{ P-value } \\
\hline & Men & Women & \\
\hline Age, years & 55.3 & 54.6 & $<0.0001$ \\
\hline Systolic blood pressure, $\mathrm{mm} \mathrm{Hg}$ & 133.1 & 130.0 & $<0.0001$ \\
\hline Diastolic blood pressure, $\mathrm{mm} \mathrm{Hg}$ & 80.5 & 77.3 & $<0.0001$ \\
\hline Hypertension medication use (\%) & 16.0 & 17.9 & 0.0001 \\
\hline Glucose, mg per $100 \mathrm{ml}$ & 109.6 & 101.8 & $<0.0001$ \\
\hline Diabetes medication use (\%) & 1.9 & 1.5 & 0.02 \\
\hline HDL cholesterol, mg per $100 \mathrm{ml}$ & 54.5 & 58.2 & $<0.0001$ \\
\hline Triglycerides, mg per $100 \mathrm{ml}$ & 139.8 & 118.2 & $<0.0001$ \\
\hline Body mass index, $\mathrm{kg} \mathrm{m}^{-2}$ & 23.7 & 23.8 & $<0.0001$ \\
\hline Obesity $\left(\mathrm{BMI} \geqslant 30 \mathrm{~kg} \mathrm{~m}^{-2}\right)(\%)$ & 2.3 & 4.0 & $<0.0001$ \\
\hline Total cholesterol, mg per $100 \mathrm{ml}$ & 196.0 & 209.8 & $<0.0001$ \\
\hline Current smokers (\%) & 40.2 & 2.6 & $<0.0001$ \\
\hline Heavy drinkers (\%) & 16.7 & 0.2 & $<0.0001$ \\
\hline \multicolumn{4}{|l|}{ Metabolic syndrome (\%) } \\
\hline Criteria based on $\mathrm{AHA} / \mathrm{NHLBI}$ & 25.0 & 22.1 & $<0.0001$ \\
\hline Criteria based on IDF & 18.5 & 16.5 & 0.0001 \\
\hline High blood pressure (\%) & 63.7 & 56.3 & $<0.0001$ \\
\hline High glucose (\%) & 29.3 & 15.5 & $<0.0001$ \\
\hline Low HDL cholesterol (\%) & 15.0 & 28.8 & $<0.0001$ \\
\hline High triglycerides (\%) & 30.7 & 22.7 & $<0.0001$ \\
\hline Overweight (\%) & 31.2 & 33.4 & 0.0005 \\
\hline
\end{tabular}

Analysis of covariance and Mantel-Haenszel chi-squared tests were used to compare the mean value of age and age-adjusted mean values and percentages for cardiovascular risk factors, metabolic syndrome and its components.
1.46 (1.13-1.89) for high glucose, 1.82 (1.36-2.42) for low HDL cholesterol, 1.50 (1.16-1.94) for high triglycerides and 1.44 (1.12$1.85)$ for being overweight among men. These associations were weaker among women (Table 3); the respective hazard ratios were 2.28 (1.57-3.31), 1.44 (0.99-2.08), 1.40 (1.04-1.90), 1.17 (0.83-1.65) and $1.13(0.83-1.53)$ for high blood pressure, high glucose, low HDL cholesterol, high triglycerides and for being overweight.

There was no significant excess risk of hemorrhagic stroke for any component of the metabolic syndrome, except for high blood pressure. Among men, the multivariable hazard ratio for high blood pressure was 2.75 (1.62-4.67) for hemorrhagic stroke, 2.77 (1.55-4.95) for intraparenchymal hemorrhage and $2.52(0.70-8.98)$ for subarachnoid hemorrhage. The respective hazard ratios were 3.98 (2.38-6.64), 4.75 (2.33-9.67) and 3.13 (1.48-6.58) among women.

Men with metabolic syndrome based on the AHA/NHLBI criteria ( $25.1 \%$ of the population) had a 2.3 -fold higher risk of ischemic heart disease and a 1.9-fold higher risk of ischemic stroke, although men with metabolic syndrome based on the IDF criteria $(18.5 \%$ of the population) had a non-significant excess risk of ischemic heart disease and a 1.9-fold higher risk of ischemic stroke compared with men without metabolic syndrome, after adjusting for age, study area and other cardiovascular risk factors. The multivariable hazard ratios for ischemic cardiovascular disease were 1.97 (1.54-2.51) for metabolic syndrome based on the AHA/NHLBI criteria and 1.82 (1.39-2.38) for metabolic syndrome based on the IDF criteria among men. The respective hazard ratios among women were $1.51(1.10-2.06)$ and 1.49 (1.06-2.08).

The PAFs of ischemic heart disease, total stroke and stroke subtypes were between 43 and $69 \%$ for high blood pressure among men and women; these values were much higher than those of the other components. The PAF (95\% CL) of ischemic cardiovascular disease was $19 \%(11,26)$ for the metabolic syndrome based on the AHA/ NHLBI criteria and $12 \%(6,18)$ for the metabolic syndrome based on the IDF criteria among men $(P$ for difference $=0.003)$, whereas the respective PAF among women was $12 \%(2,21)$ and $8 \%(1,16)(P$ for difference $=0.12$ ).

We found no significant excess risk of hemorrhagic stroke for the metabolic syndrome based on either the AHA/NHLBI or the IDF criteria among both men and women.

Increasing the number of metabolic syndrome components increased the risk of ischemic heart disease among men and that of ischemic stroke among men and women $(P$ for trend $<0.0001)$ (Tables 4 and 5). Although women with 1-3 components had a higher risk of hemorrhagic stroke than did women with 0 or 4 components, there was no dose-response association between the number of components of the metabolic syndrome and the risk for either sex ( $P$ for trend $>0.05$ ). Further, there was no dose-response association of the metabolic syndrome components with either intraparenchymal or subarachnoid hemorrhage ( $P$ for trend $>0.05$ ).

We also analyzed the association between the metabolic syndrome and the risk of ischemic cardiovascular disease after study participants were stratified into non-overweight and overweight individuals (Table 6). Among men, the multivariable hazard ratio of ischemic cardiovascular disease was 1.90 (1.14-3.14) in non-overweight persons with 1 risk factor (any component of the metabolic syndrome, except overweight), 2.72 (1.65-4.48) in non-overweight persons with $\geqslant 2$ risk factors, $2.23(1.21-4.11)$ in overweight persons with 1 risk factor and $3.61(2.17-6.00)$ in overweight persons with $\geqslant 2$ risk factors. The respective hazard ratios were 1.73 (0.99-3.02), 2.08 (1.19-3.64), $1.73(0.91-3.27)$ and $2.38(1.36-4.18)$ among women. The prevalence was $29 \%$ in non-overweight persons with 1 risk factor, $24 \%$ in non- 
Table 2 Sex-specific hazard ratios (95\% confidence interval) and population-attributable fraction (95\% confidence limits) of cardiovascular disease according to the metabolic syndrome based on modified criteria of the American Heart Association/National Heart, Lung, and the Blood Institute (AHA/NHLBI) and international diabetes federation (IDF) and its components among men

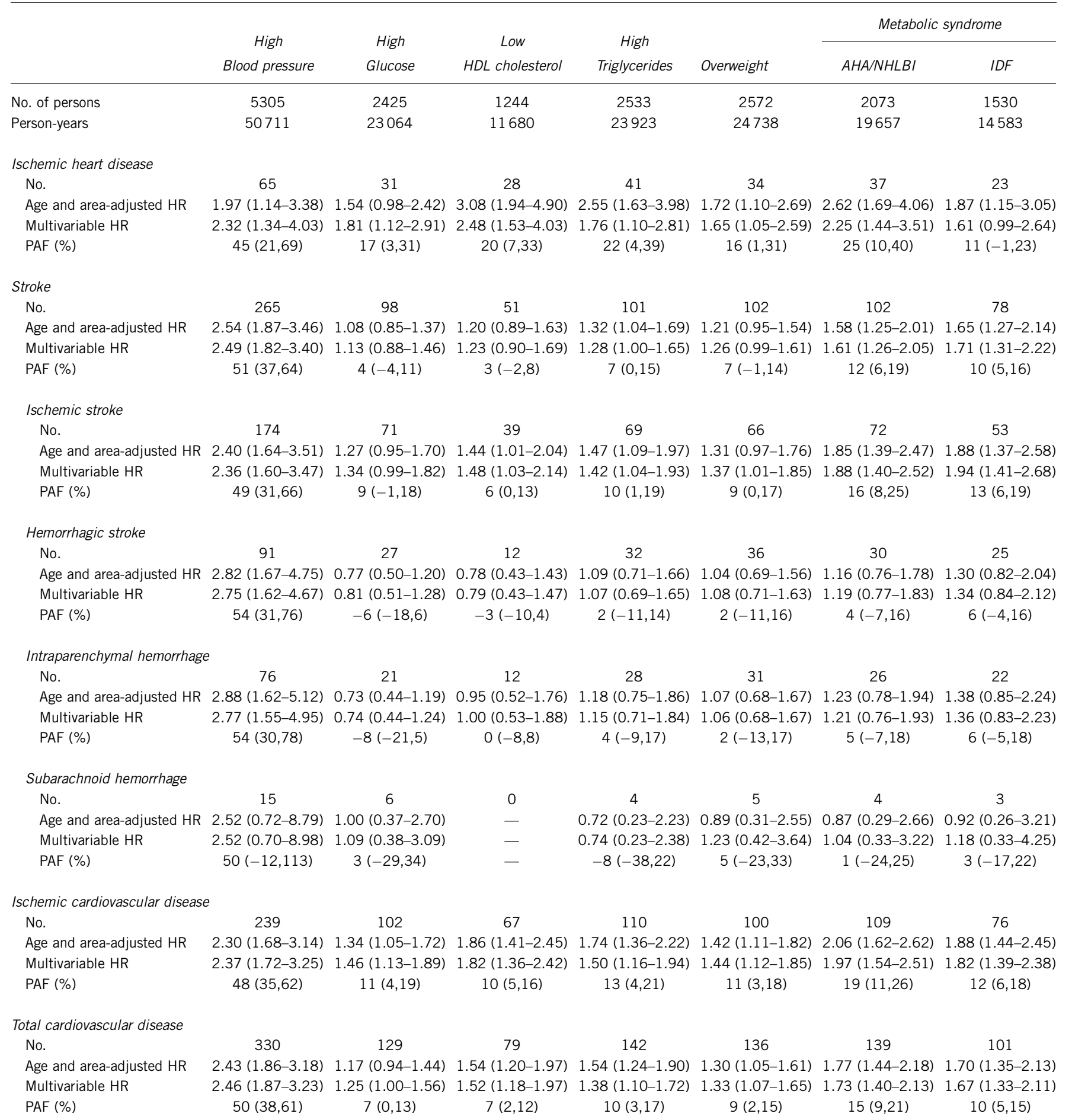

Abbreviations: HR, Hazard ratio; PAF, population-attributable fraction.

Multivariable hazard ratio was adjusted for age, study area, time since last meal, total cholesterol levels, smoking status and ethanol intake.

High blood pressure: blood pressure $\geqslant 130 / 85 \mathrm{~mm} \mathrm{Hg}$ and/or medication use.

High glucose: glucose $\geqslant 5.55 \mathrm{mmoll}^{-1}(100 \mathrm{mg}$ per $100 \mathrm{ml})$ for fasting or $\geqslant 7,77 \mathrm{mmol} \mathrm{I}^{-1}(140 \mathrm{mg}$ per $100 \mathrm{ml})$ for non-fasting, and/or on treatment.

Low HDL cholesterol: HDL cholesterol $<1.03 \mathrm{mmol}^{-1}$ ( $40 \mathrm{mg}$ per $100 \mathrm{ml}$ ) for men and $<1.29 \mathrm{mmol}^{-1}$ (50 mg per $100 \mathrm{ml}$ ) for women.

High triglycerides: high serum triglycerides $\geqslant 1.69 \mathrm{mmol}^{-1}(150 \mathrm{mg}$ per $100 \mathrm{ml})$

Overweight: $\mathrm{BMI} \geqslant 25.0 \mathrm{~kg} \mathrm{~m}^{-2}$ 
Table 3 Sex-specific hazard ratios (95\% confidence interval) and population-attributable fraction ( $95 \%$ confidence limits) of cardiovascular disease according to the metabolic syndrome based on modified criteria of the American Heart Association/National Heart, Lung, and Blood Institute (AHA/NHLBI) and the International Diabetes Federation (IDF), and its components among women

\begin{tabular}{|c|c|c|c|c|c|c|c|}
\hline & \multirow{2}{*}{$\begin{array}{c}\text { High } \\
\text { Blood pressure }\end{array}$} & \multirow{2}{*}{$\begin{array}{c}\text { High } \\
\text { Glucose }\end{array}$} & \multirow{2}{*}{$\begin{array}{c}\text { Low } \\
\text { HDL cholesterol }\end{array}$} & \multirow{2}{*}{$\begin{array}{c}\text { High } \\
\text { Triglycerides }\end{array}$} & \multirow[b]{2}{*}{ Overweight } & \multicolumn{2}{|c|}{ Metabolic syndrome } \\
\hline & & & & & & AHA/NHLBI & $I D F$ \\
\hline No. of persons & 8421 & 2327 & 4324 & 3420 & 5037 & 3315 & 2485 \\
\hline Person-years & 84048 & 23020 & 42983 & 33823 & 50310 & 32948 & 24744 \\
\hline \multicolumn{8}{|l|}{ Ischemic heart disease } \\
\hline No. & 33 & 8 & 15 & 8 & 10 & 10 & 6 \\
\hline Age and area-adjusted HR & $2.68(1.17-6.15)$ & $1.16(0.53-2.52)$ & $1.42(0.74-2.72)$ & $0.74(0.33-1.63)$ & $0.64(0.31-1.31)$ & $0.99(0.48-2.04)$ & $0.79(0.33-1.89)$ \\
\hline Multivariable HR & $2.80(1.22-6.44)$ & $1.33(0.58-3.04)$ & $1.37(0.71-2.64)$ & $0.70(0.31-1.58)$ & $0.63(0.31-1.31)$ & $1.00(0.48-2.06)$ & $0.80(0.33-1.92)$ \\
\hline PAF (\%) & $53(22,84)$ & $5(-12,22)$ & $10(-12,33)$ & $-9(-28,11)$ & $-14(-37,8)$ & $0(-19,19)$ & $-4(-18,11)$ \\
\hline \multicolumn{8}{|l|}{ Stroke } \\
\hline No. & 211 & 52 & 88 & 68 & 101 & 86 & 64 \\
\hline Age and area-adjusted HR & $2.76(2.00-3.80)$ & $1.22(0.90-1.66)$ & $1.15(0.89-1.49)$ & $1.10(0.83-1.46)$ & $1.16(0.91-1.50)$ & $1.47(1.13-1.91)$ & $1.42(1.07-1.89)$ \\
\hline Multivariable HR & $2.83(2.05-3.90)$ & $1.28(0.93-1.77)$ & $1.12(0.86-1.46)$ & $1.14(0.85-1.52)$ & $1.19(0.92-1.53)$ & $1.49(1.14-1.94)$ & $1.44(1.08-1.92)$ \\
\hline PAF (\%) & $53(40,66)$ & $4(-2,11)$ & $4(-5,12)$ & $3(-4,10)$ & $6(-3,15)$ & $11(3,19)$ & $8(1,14)$ \\
\hline \multicolumn{8}{|l|}{ Ischemic stroke } \\
\hline No. & 113 & 33 & 55 & 44 & 59 & 53 & 41 \\
\hline Age and area-adjusted HR & $2.15(1.42-3.26)$ & $1.42(0.96-2.10)$ & $1.42(1.01-1.99)$ & $1.30(0.90-1.87)$ & $1.31(0.93-1.83)$ & $1.67(1.19-2.36)$ & $1.72(1.19-2.48)$ \\
\hline Multivariable HR & $2.15(1.42-3.26)$ & $1.47(0.97-2.22)$ & $1.41(1.00-1.98)$ & $1.33(0.91-1.95)$ & $1.31(0.93-1.84)$ & $1.67(1.18-2.36)$ & $1.71(1.18-2.47)$ \\
\hline PAF (\%) & $43(23,62)$ & $7(-2,17)$ & $11(-1,23)$ & $8(-3,18)$ & $10(-2,22)$ & $15(4,26)$ & $12(3,21)$ \\
\hline \multicolumn{8}{|l|}{ Hemorrhagic stroke } \\
\hline No. & 98 & 19 & 33 & 24 & 42 & 33 & 23 \\
\hline Age and area-adjusted HR & $3.80(2.28-6.33)$ & $0.99(0.60-1.63)$ & $0.88(0.58-1.31)$ & $0.87(0.55-1.37)$ & $1.00(0.69-1.47)$ & $1.23(0.82-1.85)$ & $1.09(0.69-1.72)$ \\
\hline Multivariable HR & $3.98(2.38-6.64)$ & $1.05(0.63-1.77)$ & $0.84(0.55-1.26)$ & $0.91(0.57-1.45)$ & $1.04(0.71-1.52)$ & $1.27(0.85-1.92)$ & $1.12(0.71-1.77)$ \\
\hline PAF (\%) & $63(47,79)$ & $1(-8,9)$ & $-6(-18,7)$ & $-2(-12,8)$ & $1(-12,15)$ & $6(-5,17)$ & $2(-7,11)$ \\
\hline \multicolumn{8}{|l|}{ Intraparenchymal hemorrhage } \\
\hline No. & 61 & 14 & 16 & 15 & 27 & 19 & 14 \\
\hline Age and area-adjusted HR & $4.61(2.27-9.37)$ & $1.24(0.68-2.26)$ & $0.65(0.37-1.14)$ & $0.94(0.53-1.68)$ & $1.11(0.68-1.80)$ & $1.15(0.68-1.96)$ & $1.10(0.61-1.97)$ \\
\hline Multivariable HR & $4.75(2.33-9.67)$ & $1.23(0.66-2.30)$ & $0.65(0.37-1.14)$ & $0.97(0.53-1.76)$ & $1.13(0.69-1.83)$ & $1.16(0.68-1.98)$ & $1.11(0.61-2.00)$ \\
\hline PAF (\%) & $69(50,88)$ & $4(-8,16)$ & $-12(-27,2)$ & $-1(-13,12)$ & $4(-13,22)$ & $4(-9,17)$ & $2(-9,13)$ \\
\hline \multicolumn{8}{|l|}{ Subarachnoid hemorrhage } \\
\hline No. & 37 & 5 & 17 & 9 & 15 & 14 & 9 \\
\hline Age and area-adjusted HR & $2.98(1.42-6.27)$ & $0.63(0.25-1.62)$ & $1.29(0.71-2.36)$ & $0.77(0.37-1.61)$ & $0.87(0.46-1.61)$ & $1.36(0.72-2.57)$ & $1.07(0.52-2.23)$ \\
\hline Multivariable HR & $3.13(1.48-6.58)$ & $0.75(0.28-1.96)$ & $1.15(0.62-2.12)$ & $0.82(0.39-1.76)$ & $0.91(0.49-1.71)$ & $1.44(0.76-2.74)$ & $1.14(0.54-2.38)$ \\
\hline PAF (\%) & $55(28,82)$ & $-4(-16,8)$ & $5(-17,27)$ & $-4(-20,12)$ & $-3(-25,19)$ & $9(-9,28)$ & $2(-12,17)$ \\
\hline \multicolumn{8}{|l|}{ Ischemic cardiovascular disease } \\
\hline No. & 146 & 41 & 70 & 52 & 69 & 63 & 47 \\
\hline Age and area-adjusted HR & $2.25(1.55-3.26)$ & $1.36(0.96-1.93)$ & $1.42(1.05-1.92)$ & $1.16(0.84-1.62)$ & $1.13(0.84-1.53)$ & $1.50(1.10-2.05)$ & 1.49 (1.07-2.09) \\
\hline Multivariable HR & $2.28(1.57-3.31)$ & $1.44(0.99-2.08)$ & $1.40(1.04-1.90)$ & $1.17(0.83-1.65)$ & $1.13(0.83-1.53)$ & $1.51(1.10-2.06)$ & $1.49(1.06-2.08)$ \\
\hline PAF (\%) & $45(28,62)$ & $7(-2,15)$ & $11(0,22)$ & $4(-5,13)$ & $4(-6,15)$ & $12(2,21)$ & $8(1,16)$ \\
\hline \multicolumn{8}{|l|}{ Total cardiovascular disease } \\
\hline No. & 244 & 60 & 103 & 76 & 111 & 96 & 70 \\
\hline Age and area-adjusted HR & $2.75(2.03-3.71)$ & $1.21(0.91-1.62)$ & $1.18(0.93-1.51)$ & $1.05(0.80-1.37)$ & $1.08(0.85-1.37)$ & $1.40(1.09-1.79)$ & $1.33(1.02-1.74)$ \\
\hline Multivariable HR & $2.83(2.09-3.82)$ & $1.28(0.95-1.73)$ & $1.15(0.90-1.47)$ & $1.07(0.81-1.40)$ & $1.10(0.87-1.40)$ & $1.42(1.11-1.81)$ & 1.35 (1.03-1.77) \\
\hline PAF (\%) & $53(41,65)$ & $4(-2,11)$ & $5(-4,13)$ & $2(-5,8)$ & $3(-5,12)$ & $9(2,17)$ & $6(0,12)$ \\
\hline
\end{tabular}

Adjustment variables, abbreviations and definition of metabolic syndrome components are the same as shown in the footnotes of Table 2. 
Table 4 Sex-specific hazard ratios (95\% confidence interval) and population-attributable fraction (95\% confidence limits) of cardiovascular disease according to the number of components of the metabolic syndrome among men

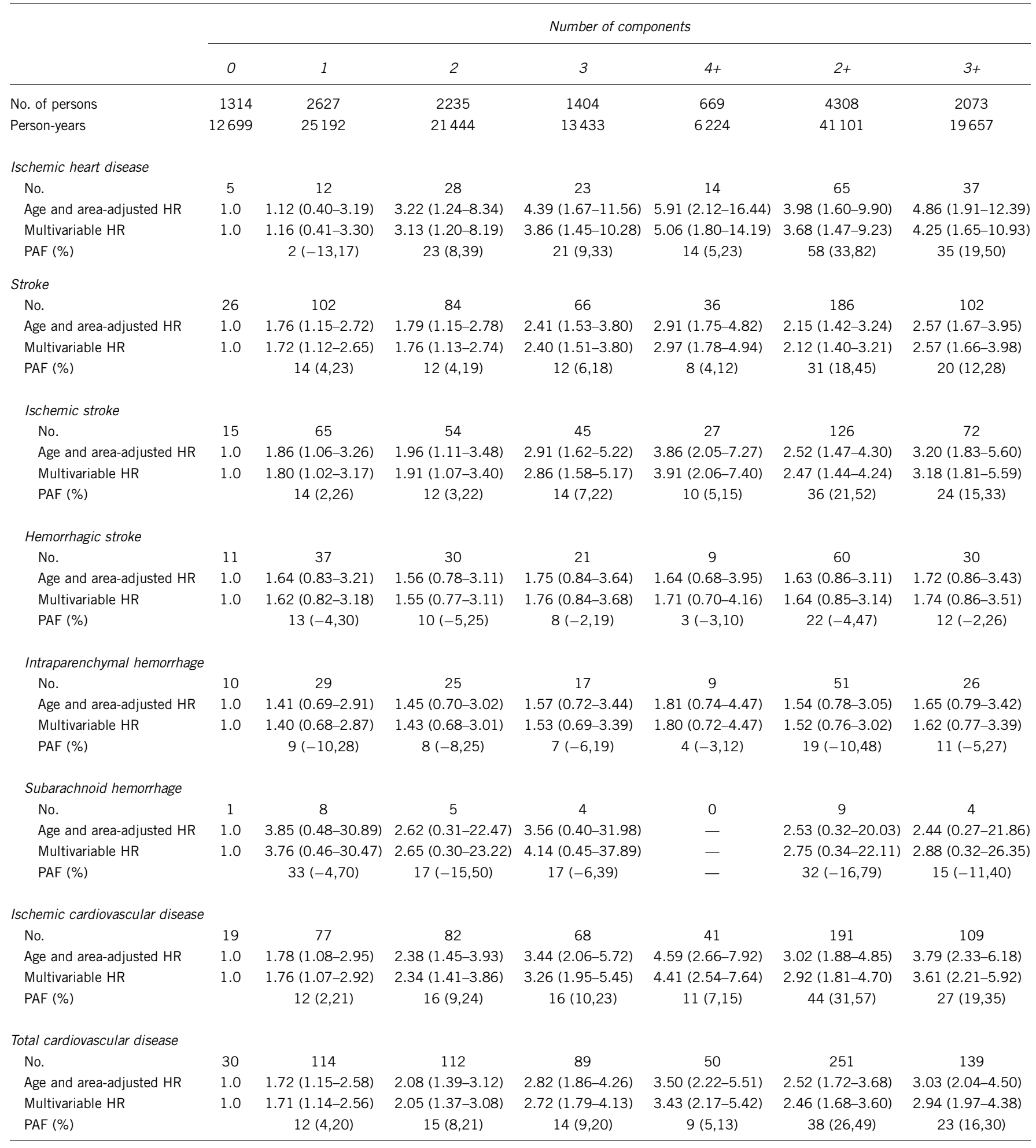

Adjustment variables, abbreviations and definition of metabolic syndrome components are the same as shown in the footnotes of Table 2 .

overweight persons with $\geqslant 2$ risk factors, $9 \%$ in overweight persons with $\geqslant 2$ risk factors and $19 \%$ in overweight persons with $\geqslant 2$ risk factors among men. The respective prevalence was $26,19,12$ and $16 \%$ among women.
Men with $\geqslant 2$ risk factors had 20\% $(12,28)$ of the PAF in ischemic cardiovascular disease among non-overweight individuals and $19 \%$ $(13,26)$ of the PAF among overweight people compared with nonoverweight people with no risk factors (as reference). The respective 
Table 5 Sex-specific hazard ratios ( $95 \%$ confidence interval) and population-attributable fraction (95\% confidence limits) of cardiovascular disease according to the number of components of the metabolic syndrome among women

\begin{tabular}{|c|c|c|c|c|c|c|c|}
\hline & \multicolumn{7}{|c|}{ Number of components } \\
\hline & 0 & 1 & 2 & 3 & $4+$ & $2+$ & $3+$ \\
\hline Person-years & 32160 & 46920 & 37868 & 21815 & 11133 & 70816 & 32948 \\
\hline \multicolumn{8}{|l|}{ Ischemic heart disease } \\
\hline Multivariable HR & 1.0 & $1.60(0.51-4.99)$ & $2.16(0.70-6.61)$ & $2.03(0.60-6.86)$ & $0.98(0.18-5.41)$ & $1.93(0.66-5.64)$ & $1.67(0.52-5.43)$ \\
\hline PAF (\%) & & $11(-14,37)$ & $19(-5,43)$ & $10(-7,27)$ & $-0(-8,8)$ & $29(-10,68)$ & $10(-12,32)$ \\
\hline \multicolumn{8}{|l|}{ Stroke } \\
\hline No. & 24 & 72 & 76 & 55 & 31 & 162 & 86 \\
\hline Age and area-adjusted HR & 1.0 & $1.70(1.07-2.71)$ & $2.01(1.26-3.19)$ & $2.38(1.46-3.86)$ & 2.55 (1.49-4.37) & $2.21(1.43-3.41)$ & $2.44(1.54-3.85)$ \\
\hline No. & 13 & 36 & 40 & 30 & 23 & 93 & 53 \\
\hline Age and area-adjusted HR & 1.0 & $1.48(0.78-2.80)$ & $1.81(0.96-3.39)$ & $2.17(1.13-4.20)$ & $3.17(1.60-6.31)$ & $2.14(1.19-3.85)$ & $2.52(1.36-4.65)$ \\
\hline Multivariable HR & 1.0 & $1.46(0.77-2.76)$ & $1.81(0.96-3.39)$ & $2.15(1.11-4.17)$ & $3.16(1.59-6.30)$ & $2.13(1.19-3.84)$ & $2.50(1.35-4.62)$ \\
\hline $\operatorname{PAF}(\%)$ & & $8(-4,20)$ & $13(0,25)$ & $11(2,21)$ & $11(4,18)$ & $35(14,56)$ & $22(10,35)$ \\
\hline \multicolumn{8}{|l|}{ Hemorrhagic stroke } \\
\hline No. & 11 & 36 & 36 & 25 & 8 & 69 & 33 \\
\hline Age and area-adjusted HR & 1.0 & $1.99(1.01-3.92)$ & $2.27(1.15-4.49)$ & $2.64(1.29-5.40)$ & $1.62(0.65-4.04)$ & $2.28(1.20-4.34)$ & $2.29(1.15-4.56)$ \\
\hline Multivariable HR & 1.0 & $2.02(1.03-3.98)$ & $2.35(1.19-4.64)$ & $2.76(1.35-5.65)$ & $1.74(0.69-4.36)$ & $2.38(1.25-4.54)$ & $2.42(1.21-4.83)$ \\
\hline PAF (\%) & & $16(2,29)$ & $18(5,30)$ & $14(5,23)$ & $3(-3,8)$ & $35(15,54)$ & $17(5,28)$ \\
\hline \multicolumn{8}{|l|}{ Subarachnoid hemorrhage } \\
\hline Age and area-adjusted HR & 1.0 & $1.36(0.51-3.59)$ & $1.55(0.58-4.13)$ & $2.38(0.88-6.44)$ & $0.76(0.15-3.82)$ & $1.68(0.69-4.13)$ & $1.83(0.69-4.84)$ \\
\hline Multivariable HR & 1.0 & $1.32(0.50-3.50)$ & $1.60(0.60-4.24)$ & $2.50(0.92-6.75)$ & $0.82(0.16-4.14)$ & $1.76(0.71-4.31)$ & $1.94(0.73-5.14)$ \\
\hline $\operatorname{PAF}(\%)$ & & $7(-17,31)$ & $11(-10,32)$ & $16(-1,33)$ & $-1(-8,6)$ & $25(-10,61)$ & $15(-6,36)$ \\
\hline \multicolumn{8}{|l|}{ Ischemic cardiovascular disease } \\
\hline No. & 17 & 48 & 54 & 38 & 25 & 117 & 63 \\
\hline Age and area-adjusted HR & 1.0 & $1.51(0.87-2.63)$ & $1.87(1.08-3.24)$ & $2.13(1.20-3.80)$ & $2.68(1.44-5.00)$ & $2.09(1.25-3.49)$ & $2.32(1.35-3.99)$ \\
\hline Multivariable HR & 1.0 & $1.49(0.86-2.60)$ & $1.88(1.09-3.26)$ & $2.13(1.19-3.81)$ & $2.68(1.43-5.01)$ & $2.09(1.25-3.50)$ & $2.32(1.35-4.00)$ \\
\hline PAF $(\%)$ & & $9(-2,20)$ & $14(3,25)$ & $11(3,19)$ & $9(3,15)$ & $34(15,52)$ & $20(9,31)$ \\
\hline \multicolumn{8}{|l|}{ Total cardiovascular disease } \\
\hline No. & 28 & 84 & 90 & 63 & 33 & 186 & 96 \\
\hline Age and area-adjusted HR & 1.0 & $1.69(1.10-2.60)$ & $2.02(1.32-3.10)$ & $2.32(1.48-3.64)$ & $2.32(1.40-3.86)$ & $2.16(1.45-3.23)$ & $2.32(1.52-3.56)$ \\
\hline Multivariable HR & 1.0 & $1.70(1.10-2.60)$ & $2.07(1.35-3.17)$ & $2.37(1.51-3.72)$ & $2.40(1.44-4.00)$ & $2.22(1.48-3.31)$ & $2.38(1.55-3.65)$ \\
\hline PAF (\%) & & $12(3,20)$ & $16(8,24)$ & $12(6,18)$ & $6(2,11)$ & $34(21,47)$ & $19(11,27)$ \\
\hline
\end{tabular}

Adjustment variables, abbreviations and definition of metabolic syndrome components are the same as shown in the footnotes of Table 2.

PAFs were $14 \%(4,23)$ and $15 \%(6,24)$ among women. Non-overweight persons with $\geqslant 1$ risk factors represented $33 \%(18,47)$ of the PAF with regard to ischemic cardiovascular disease among men and
$25 \%(8,41)$ of the PAF among women, whereas overweight persons with $\geqslant 1$ risk factors represented $23 \%(15,32)$ of the PAF among men and $20 \%(8,32)$ of the PAF among women (data not shown). 
Table 6 Sex-specific hazard ratios (95\% confidence interval) and population-attributable fraction (95\% confidence limits) of ischemic cardiovascular disease according to the number of components of the metabolic syndrome (except overweight) stratified by overweight $\left(B M I \geqslant 25 \mathrm{~kg} \mathrm{~m}^{-2}\right)$

\begin{tabular}{|c|c|c|c|c|c|c|}
\hline & \multicolumn{3}{|c|}{$\begin{array}{c}B M I<25 \mathrm{kgm}^{-2} \\
\text { Number of components except overweight }\end{array}$} & \multicolumn{3}{|c|}{$\begin{array}{c}B M I \geqslant 25 \mathrm{~kg} \mathrm{~m}^{-2} \\
\text { Number of components except overweight }\end{array}$} \\
\hline & 0 & 1 & $2+$ & 0 & 1 & $2+$ \\
\hline \multicolumn{7}{|l|}{ Men } \\
\hline No. of persons & 1314 & 2357 & 2006 & 270 & 772 & 1530 \\
\hline Person-years & 12699 & 22538 & 19017 & 2654 & 7501 & 14583 \\
\hline No. & 19 & 76 & 92 & 1 & 23 & 76 \\
\hline Age and area-adjusted HR & 1.0 & $1.92(1.16-3.18)$ & $2.87(1.75-4.71)$ & $0.29(0.04-2.13)$ & $2.14(1.16-3.92)$ & $3.75(2.26-6.20)$ \\
\hline Multivariable HR & 1.0 & $1.90(1.14-3.14)$ & $2.72(1.65-4.48)$ & $0.30(0.04-2.26)$ & $2.23(1.21-4.11)$ & $3.61(2.17-6.00)$ \\
\hline $\operatorname{PAF}(\%)$ & & $13(4,21)$ & $20(12,28)$ & $-1(-2,0)$ & $4(1,8)$ & $19(13,26)$ \\
\hline \multicolumn{7}{|l|}{ Ischemic cardiovascular disease } \\
\hline No. & 17 & 48 & 48 & 0 & 22 & 47 \\
\hline Age and area-adjusted HR & 1.0 & $1.75(1.01-3.06)$ & $2.06(1.18-3.61)$ & - & $1.73(0.92-3.26)$ & $2.40(1.37-4.20)$ \\
\hline Multivariable HR & 1.0 & $1.73(0.99-3.02)$ & $2.08(1.19-3.64)$ & - & $1.73(0.91-3.27)$ & $2.38(1.36-4.18)$ \\
\hline PAF (\%) & & $11(1,21)$ & $14(4,23)$ & - & $5(-1,11)$ & $15(6,24)$ \\
\hline
\end{tabular}

Adjustment variables, abbreviations and definition of metabolic syndrome components were the same as shown at footnotes of Table 2 .

\section{DISCUSSION}

In this large population-based prospective study of Japanese people, we observed significant associations of the metabolic syndrome with the risk of ischemic heart disease and ischemic stroke, but not with hemorrhagic stroke. People with the metabolic syndrome had 1.5- to 2.0-fold higher risks of ischemic cardiovascular disease than people without it, and the contribution of the metabolic syndrome to ischemic cardiovascular disease was between 8 and 19\%. However, the excess risks of or contributions to cardiovascular disease did not exceed those of high blood pressure.

The magnitude of the relative risks of the metabolic syndrome for total cardiovascular incidence and stroke incidence was smaller in our study than in earlier meta-analyses. There was no association between the metabolic syndrome and incidence of ischemic heart disease among women; the relative risk ranged from 1.5 to 2.2 for the incidence of cardiovascular disease, was 1.8 for the incidence of stroke and ranged from 1.5 to 1.6 for the incidence of ischemic heart disease. ${ }^{15,16}$

The contribution of the metabolic syndrome based on the modified criteria of the IDF was lower than that based on the modified criteria of the AHA/NHLBI. The weaker predictive value was because of the inclusion of a high-risk group among non-overweight persons. An earlier study among the Korean population showed that the IDF criteria failed to detect $44.9 \%$ of men and $16.6 \%$ of women with the metabolic syndrome identified by the revised NCEP/ATP criteria, because of the mis-identification of non-obese high-risk persons. ${ }^{31}$ In our Japanese population, non-overweight persons with $\geqslant 2$ risk factors constituted a large proportion of the population $(24 \%$ in men and $19 \%$ in women). The PAFs for ischemic cardiovascular disease among non-overweight people with $\geqslant 2$ risk factors were $20 \%$ in men and $14 \%$ in women, similar to or larger than those among overweight people with $\geqslant 2$ risk factors.
Moreover, non-overweight men with one risk factor represented a similarly large PAF for cardiovascular disease, whereas overweight men with one risk factor did not. An earlier study also showed that nonoverweight persons with one risk factor had a 2.0-fold higher risk of cardiovascular death. ${ }^{14}$ In our study, high blood pressure exhibited a higher contribution with regard to the incidence of cardiovascular disease compared with other components of the metabolic syndrome. Earlier studies support the importance of hypertension as a component of the metabolic syndrome and as a risk factor for the development of cardiovascular disease. ${ }^{32-34}$ These data suggested that an effect of non-clustered risk factors, such as high blood pressure, should also be taken into account for the prevention of cardiovascular disease among Japanese people, characterized by a low prevalence of obesity.

Metabolic syndrome, as defined by the Japanese committee (Committee to Evaluate Diagnostic Standards for Metabolic Syndrome), ${ }^{7,17}$ as well as by the IDF, is a condition in obese persons with certain cardiovascular risk factors. Non-obese persons can therefore be considered not to have the metabolic syndrome, even if they possess any of those cardiovascular risk factors. Our finding showed that these criteria, based on the presence of obesity, dismiss high-risk populations that are not overweight.

There was no dose-response association between the metabolic syndrome and the risk of hemorrhagic stroke. This finding was expected because hemorrhagic stroke has different pathological mechanisms, ${ }^{19}$ than those involved in ischemic heart disease or ischemic stroke. Further, being overweight is not associated with the risk of hemorrhagic stroke. ${ }^{18}$

The strengths of this study include the large population-based sample of middle-aged men and women and the use of standardized methods for the measurement of serum lipids and risk characteristics. The stroke surveillance was almost complete and a high 
percentage of stroke events was confirmed using imaging studies (97\%).

The limitations of the study were, first, that we did not measure waist circumference at the baseline survey. However, earlier studies have shown that a BMI of $25.0 \mathrm{~kg} \mathrm{~m}^{-2}$ is equal to the $100 \mathrm{~cm}^{2}$ of visceral fat area that defines central obesity, ${ }^{23}$ and that an increased risk of cardiovascular disease or that of ischemic heart disease was observed only among people with $\mathrm{BMI} \geqslant 25 \mathrm{~kg} \mathrm{~m}^{-2} .{ }^{18}$ Second, we used non-fasting data, in particular non-fasting serum triglycerides $\geqslant 1.69 \mathrm{mmoll}^{-1}(150 \mathrm{mg}$ per $100 \mathrm{ml})$, as a component of the metabolic syndrome. Although the justification for the use of the same cutoff point as fasting status is debated, the data represented by nonfasting triglycerides can be used because of its significant predictive ability with regard to ischemic heart disease. ${ }^{35}$

In conclusion, this study provides epidemiological evidence that the metabolic syndrome was associated with the risks of ischemic heart disease and ischemic stroke, but not with the risk of hemorrhagic stroke. The metabolic syndrome based on the AHA/NHLBI criteria predicts the risk of ischemic cardiovascular disease better than that based on the IDF criteria among less-obese populations. This is because non-overweight people with cardiovascular risk factors are also at a high risk for ischemic heart disease and stroke.

\section{ACKNOWLEDGEMENTS}

This study was supported by Grants-in-aid for Cancer Research and for the Third Term Comprehensive Ten-Year Strategy for Cancer Control from the Ministry of Health, Labor and Welfare of Japan. The authors thank all staff members in each study area and in the central office for their painstaking efforts in conducting the baseline survey and follow-up. Hiroyuki Noda was also supported by the post-doctoral fellowship program of the Uehara Memorial Foundation in 2007 (Tokyo, Japan).

\section{CONFLICT OF INTEREST}

The authors declare no conflict of interest.

\section{STUDY GROUP MEMBERS}

Members of the Japan Public Health Center-based Prospective Study (JPHC Study, principal investigator: S Tsugane) Group are: S Tsugane, $\mathrm{M}$ Inoue, $\mathrm{T}$ Sobue and T Hanaoka, National Cancer Center, Tokyo; J Ogata, S Baba, T Mannami, A Okayama and Y Kokubo, National Cardiovascular Center, Osaka; K Miyakawa, F Saito, A Koizumi, Y Sano, I Hashimoto and T Ikuta, Iwate Prefectural Ninohe Public Health Center, Iwate; Y Miyajima, N Suzuki, S Nagasawa, Y Furusugi and N Nagai, Akita Prefectural Yokote Public Health Center, Akita; H Sanada, Y Hatayama, F Kobayashi, H Uchino, Y Shirai, T Kondo, R Sasaki, Y Watanabe, Y Miyagawa and Y Kobayashi, Nagano Prefectural Saku Public Health Center, Nagano; Y Kishimoto, E Takara, T Fukuyama, M Kinjo, M Irei and H Sakiyama, Okinawa Prefectural Chubu Public Health Center, Okinawa; K Imoto, H Yazawa, T Seo, A Seiko, F Ito,and F Shoji, Katsushika Public Health Center, Tokyo; A Murata, K Minato, K Motegi and T Fujieda, Ibaraki Prefectural Mito Public Health Center, Ibaraki; K Matsui, T Abe, M Katagiri and M Suzuki, Niigata Prefectural Kashiwazaki and Nagaoka Public Health Center, Niigata; M Doi, A Terao, Y Ishikawa and T Tagami, Kochi Prefectural Chuo-higashi Public Health Center, Kochi; H Sueta, H Doi, M Urata, N Okamoto and F Ide, Nagasaki Prefectural Kamigoto Public Health Center, Nagasaki; H Sakiyama, $\mathrm{N}$ Onga, H Takaesu and M Uehara, Okinawa Prefectural Miyako Public Health Center, Okinawa; F Horii, I Asano, H Yamaguchi,
K Aoki, S Maruyama, M Ichii and M Takano, Osaka Prefectural Suita Public Health Center, Osaka; Y Tsubono, Tohoku University, Miyagi; K Suzuki, Research Institute for Brain and Blood Vessels Akita, Akita; Y Honda, K Yamagishi and S Sakurai, Tsukuba University, Ibaraki; M Kabuto, National Institute for Environmental Studies, Ibaraki; M Yamaguchi, Y Matsumura, S Sasaki and S Watanabe, National Institute of Health and Nutrition, Tokyo; M Akabane, Tokyo University of Agriculture, Tokyo; T Kadowaki, Tokyo University, Tokyo; M Noda, International Medical Center of Japan, Tokyo; Y Kawaguchi, Tokyo Medical and Dental University, Tokyo; Y Takashima, Kyorin University, Tokyo; K Nakamura, Niigata University, Niigata; S Matsushima and S Natsukawa, Saku General Hospital, Nagano; H Shimizu, Sakihae Institute, Gifu; H Sugimura, Hamamatsu University, Shizuoka; S Tominaga, Aichi Cancer Center Research Institute, Aichi; $\mathrm{H}$ Iso, Osaka University, Osaka; M Iida, W Ajiki and A Ioka, Osaka Medical Center for Cancer and Cardiovascular Disease, Osaka; S Sato, Osaka Medical Center for Health Science and Promotion, Osaka; E Maruyama, Kobe University, Hyogo; M Konishi, K Okada and I Saito, Ehime University, Ehime; N Yasuda, Kochi University, Kochi; S Kono, Kyushu University, Fukuoka.

1 Eckel RH, Grundy SM, Zimmet PZ. The metabolic syndrome. Lancet 2005; 365 : 1415-1428.

2 Alberti KG, Zimmet P, Shaw J, IDF Epidemiology Task Force Consensus Group. The metabolic syndrome - a new worldwide definition. Lancet 2005; 366: 1059-1062.

3 Alberti KG, Zimmet PZ. Definition, diagnosis and classification of diabetes mellitus and its complications. Part 1: diagnosis and classification of diabetes mellitus provisional report of a WHO consultation. Diabet Med 1998; 15: 539-553.

4 Expert Panel on Detection, Evaluation, and Treatment of High Blood Cholesterol in Adults. Executive Summary of The Third Report of The National Cholesterol Education Program (NCEP) Expert Panel on Detection, Evaluation, And Treatment of High Blood Cholesterol In Adults (Adult Treatment Panel III). JAMA 2001; 285: 2486-2497.

5 Grundy SM, Cleeman JI, Daniels SR, Donato KA, Eckel RH, Franklin BA, Gordon DJ, Krauss RM, Savage PJ, Smith Jr SC, Spertus JA, Costa F, American Heart Association, National Heart, Lung, and Blood Institute. Diagnosis and management of the metabolic syndrome: an American Heart Association/National Heart, Lung, and Blood Institute Scientific Statement. Circulation 2005; 112: 2735-2752.

6 Alberti KG, Zimmet P, Shaw J. Metabolic syndrome-a new world-wide definition. A consensus statement from the International Diabetes Federation. Diabet Med 2006; 23: 469-480.

7 Committee to Evaluate Diagnostic Standards for Metabolic Syndrome. Definition and the diagnostic standard for metabolic syndrome: Committee to Evaluate Diagnostic Standards for Metabolic Syndrome. Nippon Naika Gakkai Zasshi 2005; 94: 794-809.

8 Mizushima S. New health assessment and life style modification advice program for metabolic syndrome in Japan. Nippon Rinsho 2006; 64(Suppl 9): 729-733.

9 Bjorntorp P. Abdominal obesity and the metabolic syndrome. Ann Med 1992; 24 : 465-468.

10 McNeill AM, Schmidt MI, Rosamond WD, Girman CJ, Golden SH, East HE, Ballantyne $\mathrm{CM}$, Heiss G. The metabolic syndrome and 11-year risk of incident cardiovascular disease in the atherosclerosis risk in communities study. Diabetes Care 2005; 28 : 385-390.

11 Hunt KJ, Resendez RG, Williams K, Haffner SM, Stern MP, San Antonio Heart Study. National Cholesterol Education Program versus World Health Organization metabolic syndrome in relation to all-cause and cardiovascular mortality in the San Antonio Heart Study. Circulation 2004; 110: 1251-1257.

12 Malik S, Wong ND, Franklin SS, Kamath TV, L'Italien GJ, Pio JR, Williams GR. Impact of the metabolic syndrome on mortality from coronary heart disease, cardiovascular disease, and all causes in United States adults. Circulation 2004; 110: 1245-1250.

13 Iso H, Sato S, Kitamura A, Imano H, Kiyama M, Yamagishi K, Cui R, Tanigawa T, Shimamoto T. Metabolic syndrome and the risk of ischemic heart disease and stroke among Japanese men and women. Stroke 2007; 38: 1744-1751.

14 Kadota A, Hozawa A, Okamura T, Kadowak T, Nakmaura K, Murakami Y, Hayakawa T, Kita Y, Okayama A, Nakamura Y, Kashiwagi A, Ueshima H, NIPPON DATA Research Group. Relationship between metabolic risk factor clustering and cardiovascular mortality stratified by high blood glucose and obesity: NIPPON DATA90, 19902000. Diabetes Care 2007; 30: 1533-1538.

15 Galassi A, Reynolds K, He J. Metabolic syndrome and risk of cardiovascular disease: a meta-analysis. Am J Med 2006; 119: 812-819.

16 Gami AS, Witt BJ, Howard DE, Erwin PJ, Gami LA, Somers VK, Montori VM. Metabolic syndrome and risk of incident cardiovascular events and death: a systematic review and meta-analysis of longitudinal studies. J Am Coll Cardiol 2007; 49: 403-414. 
17 Takeuchi H, Saitoh S, Takagi S, Ohnishi H, Ohhata J, Isobe T, Shimamoto K. Metabolic syndrome and cardiac disease in Japanese men: applicability of the concept of metabolic syndrome defined by the National Cholesterol Education Program-Adult Treatment Panel III to Japanese men-the Tanno and Sobetsu Study. Hypertens Res 2005; 28: 203-208.

18 Cui $\mathrm{R}$, Iso $\mathrm{H}$, Toyoshima $\mathrm{H}$, Date $\mathrm{C}$, Yamamoto A, Kikuchi S, Kondo $T$, Watanabe $\mathrm{Y}$, Koizumi A, Wada Y, Inaba Y, Tamakoshi A, JACC Study Group. Body mass index and mortality from cardiovascular disease among Japanese men and women: the JACC study. Stroke 2005; 36: 1377-1382.

19 Ooneda G. Pathology of stroke. Jpn Circ J 1986; 50: 1224-1234.

20 Chei $\mathrm{CL}$, Iso H, Yamagishi K, Inoue M, Tsugane S. Body mass index and weight change since 20 years of age and risk of coronary heart disease among Japanese: the Japan Public Health Center-Based Study. Int J Obes 2008; 32: 144-151.

21 Tsugane S, Gey F, Ichinowatari Y. Cross-sectional epidemiologic study for assessing cancer risks at the population level. I. Study design and participation rate. Epidemiology 1992; 2: 75-81.

22 Nakamura M, Sato S, Shimamoto T. Improvement in Japanese clinical laboratory measurements of total cholesterol and HDL-cholesterol by the US Cholesterol Reference Method Laboratory Network. J Atheroscler Thromb 2003; 10: 145-153.

23 Examination Committee of Criteria for 'Obesity Disease' in Japan, Japan Society for the Study of Obesity. New criteria for 'obesity disease' in Japan. Circ J 2002; 66: 987-992.

24 Yamagishi K, Ikeda A, Iso H, Inoue M, Tsugane S. Self-reported stroke and myocardial infarction had adequate sensitivity in a population-based prospective study (JPHC Study). J Clin Epidemiol 2008 (e-pub ahead of print 23 December 2008).

25 Iso H, Kobayashi M, Ishihara J, Sasaki S, Okada K, Kita Y, Kokubo Y, Tsugane S, JPHC Study Group. Intake of fish and n3 fatty acids and risk of coronary heart disease among Japanese: the Japan Public Health Center-Based (JPHC) Study Cohort I. Circulation 2006; 113: 195-202.

26 Tunstall-Pedoe H, Kuulasmaa K, Amouyel P, Arveiler D, Rajakangas AM, Pajak A, WHO MONICA Project. Myocardial infarction and coronary deaths in the World Health
Organization MONICA Project: registration procedures, event rates and case fatality in 38 populations from 21 countries in 4 continents. Circulation 1994; 90: 583-612.

27 Walker AE, Robins M, Weinfeld FD. The National Survey of Stroke. Clinical findings. Stroke 1981; 12(Suppl 1): I13-144.

28 Iso $\mathrm{H}$, Rexrode $\mathrm{K}$, Hennekens $\mathrm{CH}$, Manson JE. Application of computer tomographyoriented criteria for stroke subtype classification in a prospective study. Ann Epidemiol 2000; 10: 81-87.

29 Rockhill B, Newman B, Weinberg C. Use and misuse of population attributable fractions. Am J Public Health 1998; 88: 15-19.

30 Efron B, Tibshirani R. Bootstrap Methods for Standard Errors, Confidence Intervals, and Other Measures of Statistical Accuracy. Stat Sci 1986; 1: 54-75.

31 Yoon YS, Lee ES, Park C, Lee S, Oh SW. The new definition of metabolic syndrome by the international diabetes federation is less likely to identify metabolically abnormal but non-obese individuals than the definition by the revised national cholesterol education program: the Korea NHANES study. Int J Obes (Lond) 2007; 31: 528-534.

32 Ishizaka N, Ishizaka Y, Toda E, Hashimoto H, Nagai R, Yamakado M. Hypertension is the most common component of metabolic syndrome and the greatest contributor to carotid arteriosclerosis in apparently healthy Japanese individuals. Hypertens Res 2005; 28: 27-34.

33 Sairenchi T, Iso H, Irie F, Fukasawa N, Yamagishi K, Kanashiki M, Saito Y, Ota H, Nose T. Age-specific relationship between blood pressure and the risk of total and cardiovascular mortality in Japanese men and women. Hypertens Res 2005; 28 : 901-909.

34 Chei CL, Yamagishi K, Tanigawa T, Kitamura A, Imano H, Kiyama M, Sato S, Iso H. Metabolic syndrome and the risk of ischemic heart disease and stroke among middleaged Japanese. Hypertens Res 2008; 31: 1887-1894.

35 Iso H, Naito Y, Sato S, Kitamura A, Okamura T, Sankai T, Shimamoto T, lida M, Komachi $Y$. Serum triglycerides and risk of coronary heart disease among Japanese men and women. Am J Epidemiol 2001; 153: 490-499. 